\title{
Estimation Abilities of Senior Secondary School II Students
}

\author{
Zuya Habila Elisha,
}

\begin{abstract}
The study investigated the computational estimation ability of Senior Secondary School II students in four types of estimation tasks. The respondents were 430 male and 354 females selected from both urban and rural schools. The design of the study was a factorial one. The instrument used in the study was adopted from Rubenstein (1985) with slight modifications on four types of estimation tasks, namely: open-ended, reference number, reasonable vs unreasonable and order of magnitude estimation tasks. Sixty four items were administered in all, sixteen for each estimation type. The results of the study indicated differences in performance between boys and girls and between urban and rural students. Boys and girls differed in all the scales of estimation, except reference number scale. The results also indicated that students in urban schools differed in all except in reasonable vs unreasonable scale. Interaction effects were found to be significant and all were the ordinal type. The multiple regression generated in the study showed that the four types of estimation accounted for $41.4 \%$ of the variance in computational estimation performance. There was no significant difference in performance between form dimensions. Decimal items were more difficult than whole number items. Division and multiplication items were more difficult than addition and subtraction items. The scores of the students were especially low on the Open-ended estimation type. The study has revealed that language of estimation is yet to be understood by the students.
\end{abstract}

Keywords: Computation, Estimation; Mathematics education, Student ability

Submitted Date 21 June 2013

Accepted Date: 26 June 2013

\section{Introduction}

There seems to be a general agreement among mathematics educators that the ability to estimate the results of computations is an essential skill (National Council of Supervisors of mathematics (NCSM), 1978[1]; National Council of Teachers of Mathematics (NCTM), 1980[2]). Some have suggested that computational estimation is more commonly used than exact calculations (Carpenter, Coburn, Reys \& Wilson, 1976[3]). They also maintained that with the advent of inexpensive calculators, it has become essential for students to be able to judge the reasonableness of an answer displayed on a machine. The teaching of estimation has not become a major part of the mathematics curriculum (Dickey, 1934[4]; Trafton, 1978[5]; Schoen, Friesen, Jarret \& Urbatsch, 1981[6] and Ale, 1989 [7]). These researchers reported that teaching computational estimation would improve the skills of students at exact computations and verbal problem solving.

There have been various attempts to clarify what mathematics abilities are needed to participate successfully in adult society (Levine, 1982[8]). Therefore, the ability to estimate mentally the results of computation has appeared on many list of basic skills, including those of NCSM (1978) and NCTM (1980). The acquisition of computational estimation skills is said to consolidate and contribute to the understanding of mathematics by students in the domain of number and measurement ((Bright, 1976 and Sowder, 1992), reported in Forester \& Pike (1998 [9])). Computational estimation skills also provide an essential practical means for operating within many mathematical and everyday situations in which exact calculations or measurements are contextually defined as either impossible or unnecessary (Levine, 1982). Usiskin (1986[10]) said it is generally felt that students do not learn to estimate without formal instruction. He noted that in some cases, estimate is the only alternative to solving a problem (e.g. $\pi=3.14$ ). He also identified four reasons for estimation namely: estimates are easier to use, estimates increase clarity, estimating gives consistency and Constraints force estimates. A study conducted by Coburn \& Shulte (1986[11]) shows those students with good estimation skills are also good in over all mathematical skills. The flexibility computational estimation offers leads to better use of mathematical skills.

However, in spite of the importance of computational estimation, not only to children but to adults alike, it is a neglected area of the curriculum (Bell, 1974[12]; Carpenter et al, 1976 \& Ale, 1989). It is generally 
limited to rounding numbers (Johnson, 1979[13]), poorly motivated (Bestgen, Reys, Rybolt \& Wyatt, 1980 $[14]$ ) and it is not integrated into other curriculum topics (Carpenter et al, 1976).

Computational estimation is not limited to place value and rounding numbers, it goes beyond these.

The researcher's experience as once a teacher in the primary and secondary schools motivates him to carry out an investigation in this very important area that seems to be neglected in the curriculum or not adequately taught in the classroom. The absence of local studies in this area attests to the fact that computational estimation is viewed as just knowing place value and rounding to certain significant figures or number of decimal places and this also calls for a study of this kind.

\section{Statement Of The Problem}

It is evident from the literature reviewed so far that computational estimation is a neglected area of the curriculum, generally limited to rounding numbers, poorly motivated and not integrated in to other curriculum topics. The problem has to do with lack of attention given to the conscious teaching of estimation (Ale, 1989) and the various meanings that are associated with computational estimation (Johnson, 1979; Rubenstein, 1985 $[15]$ ). And because of the different meanings given to computational estimation, the method of instruction also seems to be inappropriate (Schoen, Friesen, Jerrett \& Urbatsch, 1981).Hence it is clear that there are problems in this area. The problem for this study therefore was to investigate computational estimation ability among Senior Secondary School II students.

\section{Purpose Of The Study}

The main purpose of the study was to investigate the computational estimation ability of senior secondary school II students. Specifically, the purposes of the study were to:

1. Asses the computational estimation ability of senior secondary school II students under the following four types of computational estimation tasks: Open-ended estimation, Reference Number estimation, Reasonable vs. Unreasonable estimation and Order of Magnitude estimation.

2. Investigate the performance of the students in the four types of computational estimation and within the dimensions of estimation.

3. Compare the performance of Senior Secondary II students on the basis of location in relation to their computational estimation ability.

4. Compare the performances of Senior Secondary II students on the basis of gender difference in relation to their computational estimation ability.

\section{Research Questions}

The following research questions were formulated to help attain the purposes of the study:

1. To what extent do Senior Secondary II Students possess computational estimation abilities in the four types of computational estimation?

2. Do Senior Secondary students perform differently in the four types of computational estimation?

3. Do students in the urban schools perform differently from those in the rural schools on computational estimation?

4. Do students differ in performance on computational estimation on the basis of gender difference?

\section{Hypotheses}

The following hypotheses were tested at the 0.05 alpha level of significance.

$\mathbf{H O}_{1}$ : There are no significant differences among the mean performances of Senior Secondary II students in the four types of computational estimation tasks.

$\mathbf{H O}_{2}$ : There is no significant difference between the mean performances of urban and rural Senior Secondary II students in computational estimation.

$\mathbf{H O}_{3}$ : There is no significant difference between the mean performances of male and female Senior Secondary II students in computational estimation.

VI.I Design of the Study.

\section{Methodology}

The design of the study is a factorial one. Specifically, the design was a $2 \times 4 \times 2$ factorial. This is so because location has two levels (urban, rural), estimation task has four levels (open-ended, reference number, reasonable vs. unreasonable, order of magnitude) and gender has two levels (male, female). 


\section{VI.II Population /Sample}

The population for the study consisted of all the Senior Secondary II students in Bauchi state of Nigeria. The proportionate random sampling technique was used in selecting both the schools and the respondents. Using this technique 16 schools, comprising of 4 urban and 12 rural, were selected. The number of respondents randomly selected was 784 , comprising of 430 males and 354 females from both urban and rural schools.

\section{VI.III Instrumentation}

In this study, a 64-item Estimation Test titled 'Computational Estimation Ability Test' was adopted from Rubenstein (1985) with slight modifications to measure performance on four types of computational estimation tasks. The test was made up of four 16-item scales, one for each type of task. The test was designed to provide data on four dimensions of computational estimation: type, form (numerical and verbal), numbers (whole and decimal) and operations (addition, subtraction, multiplication and division). The items on each scale were balanced on each of the other dimensions. And also the items were designed to be parallel to each other on the four scales. The estimation scales were:

Open-ended estimation scale: Here no answer choices were given. An answer is correct if it falls within an interval bounded by the least and greatest acceptable estimates determined by a panel of mathematics educators, using commonly accepted procedures. A sample task is given here: About how much do these cost altogether? N7.47, N1.29, N16.43 and N11.65. The acceptable interval is from N35 to N37. This sample openended estimation task is in verbal form, decimal numbers and addition operation.

Reference number estimation scale: In this scale, a number is given and the respondent is to decide whether the exact answer is larger or smaller than the reference number. The reference number is a least or greatest bound of an acceptable interval for an open-ended estimate. A sample task is given here: A pair of eye glass costs N26.95 and anther costs N55.65. The difference in price is (a) Above N20 (b) Below N20 (c) I do not know. This sample reference number estimation task is in verbal form, decimal numbers and subtraction operation.

Reasonable Vs Unreasonable estimation scale. Here the items have been presented in such away that the respondent has to decide whether a calculator displayed answer is reasonable or unreasonable. A reasonable answer is exact. An unreasonable answer is outside the bound of a correct open-ended estimate. A sample task is given here: 39x51 = 1889 . This answer looks (a) Right $\quad$ (b) Wrong (c) I do not know

This is a sample reasonable Vs unreasonable estimation task (numerical form, whole numbers, multiplication operation).

Order of Magnitude estimation scale: In this scale three options differing by powers of ten are presented and the respondent is to choose the option to which the exact answer is closest. The correct answer is within the bounds of an acceptable open-ended estimate. A sample task is given here:

$$
0.8966 \text { is closest to (a) } 0.76 \quad \text { (b) } 7.6 \text { (c) } 76
$$

A sample order of magnitude estimation task (numerical form, decimal numbers, and division operation). Each correct response was scored one point in each scale.

\section{VI.IV Methods of Data Collection}

Data pertinent to this study was collected through test administration. The instrument was administered to the respondents by the researcher with the help of their mathematics teachers. The items were presented by an overhead projector for 20 seconds each, with 5 seconds between item for students to record their answers and for the researcher to replace the transparency. For the open-ended estimation scale, the respondents recorded their answers on a narrow sheet of paper to avoid what could be described as "scratch work". For the other scales, objective score sheets were used. The open-ended estimation test was administered first, then the reference number estimation test, the reasonable Vs unreasonable estimation test and the order of magnitude estimation test. A generator and an overhead projector were provided by the researcher.

\section{VI.V Methods of Data Analysis}

Research question one was analyzed by descriptive statistics and Z-test. Research questions two, three and four concerned differences in performance. Therefore the statistical hypotheses formulated were tested. Since more than two independent variables were involved in this study, a three-way analysis of variance was conducted to determine whether there were significant differences between the variables. A $2 \times 2 \times 4$ factorial analysis of variance was carried out. When the ANOVA revealed significant effect, post hoc comparisons were conducted to find out precisely where the differences lie. 


\section{RESULTS AND DISCUSSION}

Research Question 1: To what extent do Senior Secondary II Students possess computational estimation abilities in the four types of computational estimation tasks?

This research question was formulated to attain the first purpose of the study which concerned assessing the students' estimation abilities. To answer this research question, test items reflecting the four different types of computational estimation tasks were designed and administered to the respondents. Their performances on the tests were a reflection of their abilities. Table 1 gives the means and standard deviations for the four scales and for each partition within the other three dimensions.

Table 1: Mean and Standard Deviation for Estimation Test

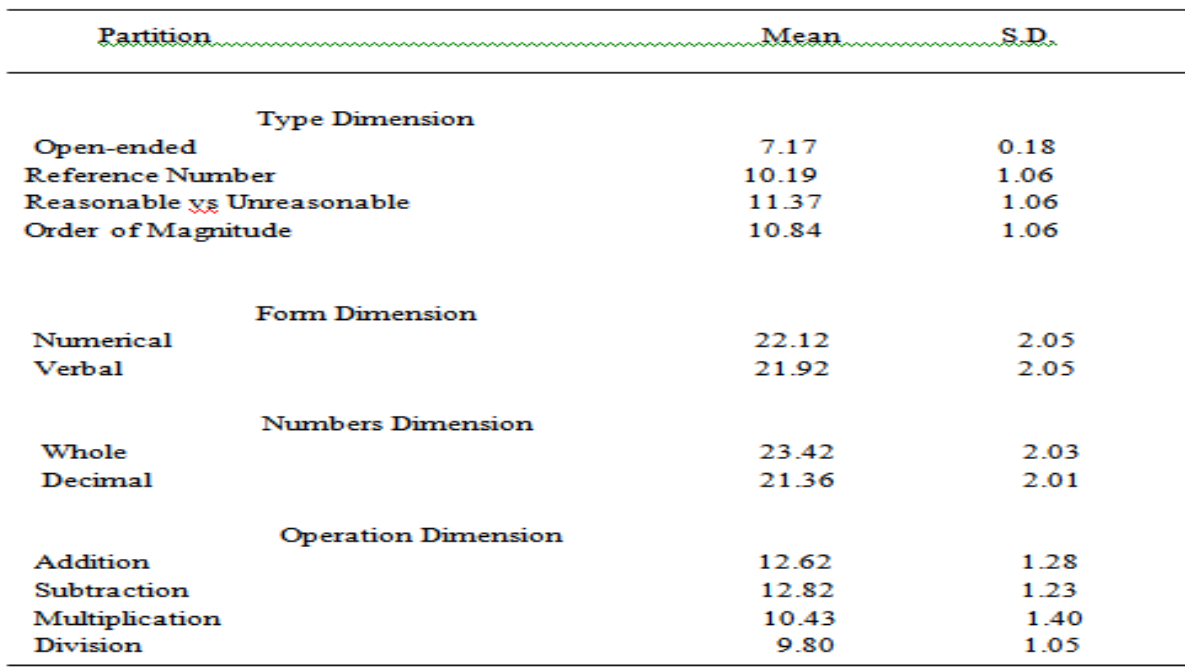

The mean scores and the standard deviations of the students were also presented on location basis. Table 2 gives the means and the standard deviations of the students by location.

Table 2: Mean Scores and Standard Deviations

\begin{tabular}{lcccc}
\hline Partition & \multicolumn{2}{c}{ Urban } & \multicolumn{2}{c}{ Rural } \\
& Mean & SD & Mean & SD \\
\hline Open-ended & 7.94 & 1.42 & 7.14 & 2.11 \\
Reference Number & 10.70 & 2.01 & 10.14 & 3.04 \\
Reas. Vs Unreas & 11.59 & 1.81 & 11.594 & 1.92 \\
Order of Magnitude & 11.38 & 2.23 & 10.92 & 1.59 \\
\hline
\end{tabular}

The mean scores and standard deviations of the students in estimation test were also presented on the basis of gender difference. Table 3 gives the mean scores and the standard deviations of estimation test by gender difference.

Table 3 Mean Scores and Standard Deviations by Gender

\begin{tabular}{lcccc}
\hline \multirow{2}{*}{ Partition } & \multicolumn{2}{c}{ Male } & \multicolumn{2}{c}{ Female } \\
& Mean & SD & Mean & SD \\
\hline Open-ended & 9.94 & 1.78 & 5.55 & 0.81 \\
Reference Number & 11.05 & 1.98 & 10.89 & 2.46 \\
Reas vs Unreas & 12.64 & 2.34 & 10.59 & 2.28 \\
Order of Magnitude & 12.17 & 2.34 & 10.99 & 4.16 \\
\hline
\end{tabular}

The questions for Reference Number, Reasonable vs Unreasonable and Order of Magnitude scales were objectives with three options each, one of which was the correct answer. So the probability of choosing a correct answer was 0.33 . A decision rule was designed to determine whether the students were simply guessing 
(i.e. the scores were due to chance) or they possess the ability to estimate (Murray \& Larry, 1999 [16]). The rule was to decide between two hypotheses, if $\mathrm{p}$ is the probability of choosing a correct response:

HO: $\mathrm{p}=0.33$, and the students were simply guessing.

HI: $p>0.33$, and the students possess estimation ability.

The Z-test was used to test the hypothesis at $\alpha=\mathrm{O} .05$ significance level. And since the interest was in the ability of the students to estimate, a one-tailed test was used. For a one-tailed test at 0.05 significance level, the mean score of the students must exceed $\mu+1.645 \sigma$ for the null hypothesis to be rejected. For true HO, the mean and standard deviation of the distribution of the scores are:

$\mu=\mathrm{np}=16(0.33)=5.28$ and $\sigma=1.73$. So, $\mu+1.645 \sigma=8.13$, and the decision rule was:

Accept the HO, if the mean score of the students was less than 8.13.

Reject otherwise.

From Table 1, the mean scores for Reference Number, Reasonable vs Unreasonable, and Order of Magnitude scales are 10.19(63.69), 11.37(71.06) and 10.84(67.75) respectively. The values in parentheses are the means of the students in estimation test out of 100. Therefore, the null hypothesis was rejected in favour of the alternative, and it was concluded that the students posses ability in the three types of estimation.

For the Open-ended scale, where no options were provided, Hoyt estimate of reliability was calculated. This is the use of analysis of variance to estimate reliability of individual scores. The Hoyt estimate of reliability was obtained as 0.72 , indicating that the scores obtained from the test in Open-ended scale were reliable. Therefore, it was concluded that the students posses ability in Open-ended estimation to some extent, since their scores on the test were reliable.

Research Question 2 : Do Senior secondary school II students perform differently in the four types and within the dimensions of computational estimation tasks?

Research question two concerned differences in performances in the four types of computational estimation tasks and within the dimensions of estimation. And to respond to this question, the following null hypothesis was formulated and tested at an alpha level of 0.05 .

$\mathbf{H O}_{1}$ : There are no significant differences between the mean scores of the students in the four types of computational estimation tasks.

To test this hypothesis, a three-way analysis of variance (ANOVA) was conducted. Table 4 gives the summary for the three-way ANOVA. Hypothesis I was rejected in favour of the alternative hypothesis. A calculated F-value of 484.99 was obtained for Estimation task as against the F-critical of 2.60. The analysis was performed using both Statistical Packages for the Social Sciences (1998) and Minitab software, and same results were obtained. The p-value 0.000 as shown in Table 4 is far below the alpha value of 0.05 , indicating high significance. Therefore, it was concluded that student performed significantly different in the four types of computational estimation tasks.

The rejection of $\mathrm{HO}_{1}$, led to post hoc comparisons using Scheffe test statistics. The post hoc comparisons using the Scheffe test statistic indicated that all the pair wise comparisons were significantly different. Table 5 gives the summary for the multiple comparisons. The p-values for all the pair wise comparisons were 0.000 as against the 0.05 for the alpha level, showing that the differences in the means were significant. Therefore, it was concluded that students performed differently in the four types of computational estimation tasks, scoring higher in Reasonable vs Unreasonable scale. The order of difficulty of the four scales, from easy to hard, was Reasonable vs Unreasonable, Order of Magnitude, Reference Number and Open-ended (Scheffe test, $\mathrm{p}<0.05$ )

Table 4 Summary for the 3-way ANOVA

\begin{tabular}{lrcccc}
\hline \multicolumn{1}{c}{ Source of variation } & $\mathrm{ss}$ & $\mathrm{df}$ & $\mathrm{ms}$ & $\mathrm{f}$ & $\mathrm{p}$ \\
\hline Location & 134.79 & 1 & 134.79 & 29.22 & 0.000 \\
Estimation Task & 6710.81 & 3 & 2236.94 & 484.99 & 0.000 \\
Gender & 773.39 & 1 & 773.39 & 167.68 & 0.000 \\
Location x Estimation & 56.04 & 3 & 18.68 & 4.05 & 0.009 \\
Location x Gender & 94.52 & 1 & 94.52 & 29.49 & 0.000 \\
Estimation x Gender & 549.63 & 3 & 183.21 & 39.72 & 0.000 \\
Loc xEst x Gender & 172.70 & 3 & 57.57 & 12.48 & 0.000 \\
Error & 14390.42 & 3120 & 4.61 & & \\
Total & 24682.35 & 3135 & & & \\
\hline
\end{tabular}


Table 5: Summary for the Scheffe Multiple Comparisons

\begin{tabular}{lccc}
\hline Task & Mean Difference & standard error & p-value \\
\hline $\mathrm{X}_{1} \vee \mathrm{X}_{2}$ & $-2.84^{*}$ & 0.11 & 0.000 \\
$\mathrm{X}_{1} \vee \mathrm{X}_{3}$ & $-4.11^{*}$ & 0.11 & 0.000 \\
$\mathrm{X}_{1} \mathrm{X}_{4}$ & $-3.59^{*}$ & 0.11 & 0.000 \\
$\mathrm{X}_{2} \mathrm{X}_{3}$ & $-1.27^{*}$ & 0.11 & 0.000 \\
$\mathrm{X}_{2} \mathrm{~V} \mathrm{X}_{4}$ & $-0.75^{*}$ & 0.11 & 0.000 \\
$\mathrm{X}_{3} \vee \mathrm{X}_{4}$ & $0.52^{*}$ & 0.11 & 0.000 \\
\hline
\end{tabular}

* The mean difference is significant $\alpha=0.05$

For the other three dimensions (Form, Numbers, Operation), there was no significant difference for Form dimension as the $\mathrm{t}$-calculated $(\mathrm{t}(1566)=1.90)$ was less than $\mathrm{t}$-critical $(1.96)$. But there were significant differences for Numbers and Operation dimensions. On the Numbers dimension, items presented with decimal numbers were more difficult than those presented with whole numbers $(\mathrm{t}(1566)=19.99)$. On the operation dimension, one-way analysis of variance was carried out to determine if the mean scores differ within themselves. A calculated F-value of 92.02 was obtained as against the F-critical value of 2.60. And also the pvalue of 0.000 was less than $a=0.05$, showing high significance. Therefore, it was concluded that the mean scores of the students on operation dimension differed significantly within themselves. Table 6 gives the summary for the analysis of variance for Operation.

Table 6 Analysis of Variance for Operation Dimension

\begin{tabular}{ccccc}
\hline Source of variation & df & ms & f & p \\
\hline Operation & 3 & 489.56 & 92.02 & 0.000 \\
Error & 3132 & 5.32 & & \\
Total & 3135 & 494.88 & & \\
& & & & \\
\hline
\end{tabular}

Since the F-test was significant, a post hoc comparison by Scheffe test was conducted. And the test indicated that all the pair wise comparisons were significantly different, except between Addition and Subtraction operations. On the operation dimension, multiplication was more difficult than either addition or subtraction; division was more difficult than multiplication. Table 7 gives the summary for the Scheffe multiple comparisons for Operation dimension.

Table 7 Scheffe Multiple Comparisons for Operation Dimension

\begin{tabular}{cccc}
\hline Operation & Mean difference & std. error & sig. \\
\hline A v S & -0.02 & 0.10 & 0.180 \\
A v M & $2.19^{*}$ & 0.10 & 0.000 \\
A v D & $2.82^{*}$ & 0.10 & 0.000 \\
S v M & $2.39^{*}$ & 0.10 & 0.000 \\
S v D & $3.02^{*}$ & 0.10 & 0.000 \\
M v D & $0.63^{*}$ & 0.10 & 0.007 \\
\hline
\end{tabular}

* The mean difference is significant at $\alpha=0.05$

Research Question 3 : Do urban and rural students perform differently in computational estimation tasks?

Research question three concerned differences in performance on the basis of location. To answer this research question, the following null hypothesis was formulated and tested:

$\mathbf{H O}_{2}$ : There is no significant difference between the mean scores of urban and rural Senior Secondary students in computational estimation.

This hypothesis was rejected in favour of the alternative hypothesis. A calculated F-value of 29.22 was obtained as against the critical F-value of 3.84, and also a p-value of 0.000 was obtained showing significance when compared with $a=0.05$. These values are shown in Table 4 . Therefore, it was concluded 
that the students differed significantly in performance in computational estimation on the basis of location, with the urban students scoring higher in total estimation test.

Since the overall F-test was significant, investigation was carried further to find out whether the difference was only in total estimation or in any type. With the t-test, a type I error is made in falsely rejecting the null hypothesis. Therefore, the Least Significant Difference (LSD) statistic which is based on the pooled error variance, and also for its appropriateness relative to the making of individual t-tests was used. The LSD value at $a=0.05$ was obtained as 0.21 .

The observed differences were:

$$
\begin{aligned}
& X_{1} u-X_{1 R}=7.94-7.14=0.80 \\
& X_{2 u}-X_{2 R}=10.70-10.14=0.56 \\
& X_{3} u-X_{3 R}=11.59-11.594=-0.004 \\
& X_{4 u}-X_{4 R}=11.38-10.92=0.46
\end{aligned}
$$

The observed differences were all greater than the LSD value, except -0.004 . These values were calculated in absolute terms. Therefore, it was concluded that urban students performed significantly different from their rural counterparts in Open-ended scale, Reference Number scale, Order of Magnitude scale, but not Reasonable vs Unreasonable scale. estimation task?

Research Question 4: Do male and female students perform differently in computational

Research question four concerned difference in performances on the basis of gender. To answer the research question, the following null hypothesis was formulated and tested at $a=0.05$ level.

$\mathbf{H O}_{3}$ : There is no significant difference between the mean scores of female students in computational estimation.

This hypothesis which was formulated to answer research question four, was rejected as the calculated F-value of 167.68 obtained was greater than the critical F-value of 3.84. Also the p-value 0.000 was less than $\mathrm{a}=0.05$, showing significance. Therefore, it was concluded that students of Senior Secondary II differ significantly in performance on the basis of gender difference.

Since the overall F-test was significant, it was investigated further to determine if the difference was only in total estimation or in any type of task. Post hoc tests are not performed for gender because there are fewer than three groups (SPSS, 1998). The Least Significant Difference test was carried out.

The observed differences were:

$$
\begin{aligned}
& \mathrm{X}_{1 \mathrm{M}^{-}} \mathrm{X}_{1 \mathrm{~F}}=9.94-5.55=4.39 \\
& \mathrm{X}_{2 \mathrm{M}}-\mathrm{X}_{2 \mathrm{~F}}=11.05-10.89=0.16 \\
& \mathrm{X}_{3 \mathrm{M}}-\mathrm{X}_{3 \mathrm{~F}}=12.64-11.59=1.05 \\
& \mathrm{X}_{4 \mathrm{M}^{-}} \mathrm{X}_{4 \mathrm{~F}}=12.17-10.99=1.18
\end{aligned}
$$

Except 0.16, all the values of the observed differences exceeded 0.21 the LSD value for $\alpha=0.05$. Therefore, it was concluded that male and female students differed significantly on Open-ended scale, Reasonable vs Umeasonable scale, Order of Magnitude scale, but not on Reference Number scale.

\section{Discussion}

The results of the present study revealed that students differ in performance within the various dimensions of computational estimation. This is in agreement with the observation made by Paull (1972) cited in Rubenstein (1985), that estimation in Mathematics is not a unitary phenomenon. The four different types of computational estimation tasks investigated in this study revealed differences in performance. On the type dimension, the order of difficulty from easy to hard was Reasonable vs Unreasonable scale, Order of Magnitude scale, Reference Number scale and Open-ended scale. This confirms a finding by Rubenstein (1985). The openended scale was especially difficult, as noted also by Rubenstein (1985) and Goodman (1991 [17]). The openended estimation items were generally difficult for the respondents, possibility because they did not estimate but tried to compute mentally before rounding to get estimate (Levine, 1982; Sowder and Wheeler, 1989 [18]). This might be so since the open-ended items had no options, the students were probably engaged in exact calculation to get estimates. The language of estimation should be stressed in the teaching and learning of estimation by classroom teachers, so that the students would be familiar with it. On the form dimension, the results of the study shows that computational estimation tasks presented in numerical form were not more difficult than those presented in verbal form. This agrees with a finding by Rubenstein (1985), but conflict with a finding by Goodman (1991). He found that performance was better on items presented in verbal form than items in numerical form. This might be as a result of differences between the respondents used in the studies. In this study the respondents were much younger. In the study by Goodman (1991), the respondents were preservice elementary school teachers. 
On the numbers dimension, estimation items presented with decimal numbers were more difficult than estimation items presented with whole numbers. This finding supports findings by several researchers (Bestgen et al, 1980; Brown, 1981 [19]; Carpenter et al, 1981; Rubenstein, 1985; Goodman, 1991). In understanding decimal, student must recognize the feature of whole numbers that are appropriate for decimal, as well as those that are not. Research studies have documented that students lack an understanding of basic decimal concept (Hiebert and Wearne, 1986 [20]; Kouba, Carpenter \& Swafford, 1989 [21]; Payne, 1984 [22]).1t is incumbent on teachers of Mathematics at primary and secondary levels to explain the concepts of decimals appropriately to their students. The use of incorrect rules for comparing decimals may be influenced by the curriculum sequence students experience (Resnick et al, $1989[23])$.

On the operation dimension, the present study has shown that estimation with multiplication and division was more difficult than estimation with addition and subtraction. Estimation with division was found to be the most difficult of all. Multiplication items were more difficult than either addition or subtraction items. This finding agrees with a finding by researchers such as Bestgen et al (1980), Levine (1982) and Rubenstein (1985). The order of difficulty for the estimation of arithmetic operation clearly reflected the conceptual difficulty those operations present, as the order they are treated in the curriculum. The present study has also revealed differences in the performances of the students on the basis of location on total estimation test. A further investigation revealed differences in three out of the four types measured in this study. This finding supports findings by Othman (1998 [24]), Igabari and Ezenweani(2006 [25]) and Worley(2003 [26]). Worley (2003) maintained that when students' self-perceived traits are matched to an environment that supports them, their academic performance may be enhanced. This better performance of the urban students might not be unconnected with the availability of learning facilities in the urban areas, such as computers and internet services. It therefore means that the performance of the rural students may also be enhanced if the environment is made supportive of learning.

The study revealed differences in performance between male and female students in total estimation, with the male student scoring higher. This confirms a finding by Rubenstein (1985). Further analysis has revealed differences in all the scales, except Reference Number scale. Rubenstein also found that male and female students did not differ in their performances in Reference Number scale. Differences in performance were more pronounced in Open-ended estimation task. Several researchers have documented gender difference in the performance of Mathematics in favour of the males (Rubenstein, 1985;Campell, 1994 [27] ;Fennema,1994 [28];Leder,1994 [29];Smith, 1996 [30];Glazer,2005 [31];Musa and Agwagah,2006 [32]). Fennema (1994) said differences exist because teachers tend to structure their classroom to favour male learners. She maintained that if the number of teachers' interactions with girls and boy were equalized, gender differences in mathematics would disappear. Arguing also from a similar perspective Leder (1994) noted that differences exist because curricula and teaching methods, traditionally are geared to the needs of males rather than females.

However, Glazer (2005) said difference exists because of differences between males and females in intrinsic aptitude. Bearing in mind these differences, the classroom teacher is expected to plan his classroom activities in such a way that the individual learner's needs are taken care of. The learning environment should be free from factors that inhibit real learning, especially for the females.

\section{Conclusion}

Interaction effects were found to be significant, and all the interactions found were the ordinal type, the kind that does not limit generalization. The one of interest is the interaction between estimation tasks and gender. Further analysis showed that there was no interaction between gender and estimation tasks except on Reference Number scale. Why the students differ in all scales on the basis of gender, except Reference Number scale calls for further investigation. For the interaction between estimation tasks and location, there was interaction at all levels except at Reasonable vs Unreasonable scale. The possible explanation may be for the pervasiveness of calculators. Both urban and rural students have access to hand calculators and so are familiar with the way calculators display answers

\section{Recommendations}

Based on the findings of the study, the following were recommended:

- Teachers should emphasize and use real world examples i.e. real life situations where only estimates are required, in teaching estimation. 
- Teachers should not require too much precision, but make the students realize that a variety of answers are possible. They should also emphasize the use of the language of estimation in their teaching.

- Teachers should make the students understand or recognize the features of whole numbers that are appropriate for decimal numbers and those that are not. The concepts of place value including tenths, hundredths, and so forth should be explained appropriately to the students.

- Teachers should make the students see situations they are familiar with used with the new language and the new notation. They should also relate the concepts of multiplication and division to those of addition and subtraction.

- Learning environment be made supportive of meaningful learning.

- Teachers should structure their learning activities to cater for individual differences, especially the female learner. This is so, as the male learners are generally faster in learning.

- Seminars/workshops should be organized for secondary school mathematics teachers.

\section{References}

[1]. National Council of Supervisors of Mathematics, Basic Mathematics Skills. Mathematics Teacher, 71, 1978,147-152.

[2]. National Council of Teachers of Mathematics, An Agenda for Action. Recommendations for School Mathematics of the 1980s ( Reston, V A: Author, 1980)

[3]. T.P. Carpenter, T.G. Coburn, R.E. Reys, and J.W. Wilson, Notes from National Assessment: Estimation, Arithmetic Teacher. 23, 1976, 296-302.

[4]. J.W. Dickey, The Value of Estimating answers to Arithmetic Problems and Examples, Elementary School Journal, 35, $1934,24-31$.

[5]. P.R. Trafton, Estimation and Mental Arithmetic: Important Components of Computation in M.N Suyd and RE. Reys (Ed.), Developing Computational Skills (Reston, V.A: National Council of Teachers of Mathematics, 1978), 196-213.

[6]. H.L Schoen,. C.D. Friesen, I.A. Jarrett and T.D.Urbatsch, Instruction in Estimating Solutions of Whole Number Computations, Journal for Research in Mathematics Education. 1 (2), 1981,165-177.

[7]. S.O. Ale, Estimation Abilities, International Journal of Mathematics Education in Science and Technology 20 (1). 1989.

[8]. D.R. Levine, Strategy Use and Estimation Ability of College Students, Journal for Research in Mathematics Education, 1982,350-359.

[9]. M.A. Forrester, and C.D. Pike, Learning to Estimate in the Mathematics Classroom. A Conversation- Analytic Approach, Journal for Research in Mathematics Education,29 (1), 1998, 334-356.

[10]. Z. Usiskin, Reasons for Estimating, in H.L. Schoeen, and M.J. Zweng, (Ed.) Estimation and Mental Computation (Reston, V A: National Council of Teachers of Mathematics, 1986) 1-15.

[11]. T.G Coburn, A.P. Shulte, Estimation in Measurement in H.J. Schoen, and M.J. Zweng, (Ed.) Estimation and Mental Computation ( Reston V. A: National Council of Teacher of Mathematics,1986) 195-203

[12]. M.S. Bell, What does "Everyman" Really Need from School Mathematics? Mathematics Teacher, 67,1974,19-20.

[13]. D.C. Johnson, Teaching Estimation and Reasonableness of Results, Arithmetic Teacher. 27 (1), 1979.

[14]. R. J. Bestgen, R.E. Reys, J.F., Rybolt, and J.W. Wyatt, Effectiveness of Systematic Instruction on Attitudes and Computational Estimat ion Skills of Pre-service Elementary Teachers, Journal of Research in Mathematics Education, 11, 1980,123-135.

[15]. R.N. Rubenstein, Computational Estimation and Related Mathematical Skills, Journal for Research in Mathematics Education. 16 (2), 1985, 106-119. RS.

[16]. Murray, and J.S. Larry, Theory and Problems of Statistics. ${ }^{\text {rd }}$ edition. (Schaum's Outlines Series. McGraw-Hill, 1999)216-237.

[17]. T. Goodman, Computational Estimation Skills of Pre-Service Elementary Teachers. Journal of Mathematical Education in Science and Technology 22 (2), 1991, 259-272.

[18]. J. T. Sowder, and M. M. Wheeler, The Development of Concepts and Strategies used in Computational Estimation, Journal for Research in Mathematics Education, 20, 1989,130-146.

[19]. M. Brown, Place value and Decimals in J. Hart (Ed.) Children's Understanding of Mathematics ( London John Murray, 1981), 48-65.

[20]. J. Heibert, and D. Wearne, Procedures over Concepts: The acquisition of Decimal Number Knowledge in H. Hiebert, (Ed.) Conceptual and Procedural Knowledge: The case of Mathematics (Hillsdale, N.H.J: Lawrence Erlbaum Associates, 1986), 199-223.

[21]. V.L. Kouba, T. P. Carpenter and J. O. Swafford, Number and Operations in M.M. Lindquist (Ed.) Results from the fourth Mathematics Assessment of the National Assessment of Educational Progress ( Reston VA: NCTM, 1989) 64-93.

[22]. J. N. Payne, Curricular Issues: Teaching Rational Numbers. Arithmetic Teacher, 31(6), 1984,14-17.

[23]. L.R. Resnick, P. Nesher, F. Leonard, M. Magone, S. Omanson and I. Peled, Conceptual Bases of Arithmetic Errors: The Case of Decimal Fractions, Journal for Research in Mathematics Education. 20,1989, 8-29.

[24]. T.G. Othman, Mathematical Ability Among Senior Secondary School I Students of the North-East Sub-Region of Nigeria, doctoral diss., Abubakar Tafawa Balewa University, Bauchi,1998.

[25]. J.N. Igabari, and U.L. Ezenweani, On e-Learning: Universal Basic Education and Primary Schools in Delta State, Proceeding of Annual National Conference of Mathematical Association of Nigeria, 2006,152-159.

[26]. P. Worley,Cohort Study of Examination Performance of Undergraduate Medical Students Learning in Community Settings. Medical Education Publication, 2003.

[27]. P.B. Campbell, Gender Equity in Mathematics Moving Forward, Backward, or Going Nowhere Fast. A Paper Presented at the Meeting of the American Education Research Association, New Orleans. L.A. 1994

[28]. E. Fennema, Old and New Perspectives on Gender and Mathematics. Paper Presented at the Meeting of the American Educational Research Association. New Orleans, LA. 1994.

[29]. G. Leder, Research on Gender and Mathematics: Perspective: A New Direction. Paper Presented at the Meeting of the American Educational Research Association. New Orleans, 1994.

[30]. I.D. Smith, Gender Differences in Academic Achievement and Self-Concept in Same-sex Schools. Australian Research Council Institute Grants Scheme. 1986.

[31]. S. Glazer, Gender and Learning Center for Quality, Research on Gender Learning ,(University of Western Australia, 2005).

[32]. D.C. Musa, and U. N. V. Agwagah, Effect of Incorporating Practical into Mathematics Evaluation on Secondary School Students' Achievement in Mathematics, ABACUS: The Mathematical Association of Nigeria, 31 (1), 2006,55-66. 